\title{
PETROGRAFIA E GEOQUÍMICA DOS DIQUES FÉLSICOS E MÁFICOS ASSOCIADOS AO BATÓLITO PELOTAS NA REGIÃO DE PIRATINI, RS
}

\author{
CELÍ ZANON ${ }^{1}$, RÔMULO MACHADO ${ }^{2}$ \& RUY PAULO PHILIPP ${ }^{3}$
}

\begin{abstract}
Petrographic studies on the mafic and felsic dykes from the Piratini region, RS, reveal a porphyritic texture with an aphanitic to fine-grained matriz, with glomeroporphyritic and spherulitic textures in the case of felsic, and ophitic to sub-ophitic with myrmekitic intergrowths in the case of mafic dykes. These dykes are intrusive in granitic rocks of the Pelotas Batholith along NW-SE and N-S trends associated with high angle shear zones. They are strongly metaluminous (mafic) and slighty metaluminous to peraluminous (felsic), with an alumina saturation index between 0.60 and 0,65 and 0,75 and 1,2 , respectively. The $\mathrm{SiO}_{2}$ content in the mafic dykes varies from 44 to $48 \mathrm{wt} \%$ and in the felsic varies from 67 to $75 \mathrm{wt} \%$. The mafic dykes present higher $\mathrm{Ti}, \mathrm{Mg}$, $\mathrm{Ca}, \mathrm{Fe}, \mathrm{Mn}$ and $\mathrm{P}$ contents in comparison with the felsic dykes. The behavior of several major and trace elements $(\mathrm{Fe}, \mathrm{Mn}, \mathrm{Mg}$, $\mathrm{Ti}, \mathrm{P}, \mathrm{Ca}$ and $\mathrm{Sr}$, and, in minor degree, $\mathrm{Ca}$ and $\mathrm{Mg}$ show the importance of crystallization of iron-magnesium and feldspars in both dykes. The $\mathrm{Nb} / \mathrm{Ta}$ e U/Th ratios of trace elements of these rocks show evidence of crustal contamination. The HREE display sub horizontallized patterns, showing $\mathrm{Tb} / \mathrm{Lu}$ ratios from 1,5 to 2,7 in the samples of mafic dykes and from 1,6 to 2,5 in the felsic dykes. The samples have shown Lu concentration from $0,3 \mathrm{ppm}$ to $0,6 \mathrm{ppm}$ in mafic, and from $18 \mathrm{ppm}$ to $41 \mathrm{ppm}$ in the felsic dykes, respectively. The felsic dykes are more enriched in LREE, with La values from $73 \mathrm{ppm}$ to $155 \mathrm{ppm}$, whereas mafic dykes present $18 \mathrm{ppm}$ to $41 \mathrm{ppm}$ of $\mathrm{La}$ and $\mathrm{La} / \mathrm{Sm}$ ratios in the range of 3,0 to 5,0 .
\end{abstract}

Keywords: Pelotas Batholith, felsic and mafic dykes, petrography, geochemistry.

\begin{abstract}
Resumo Estudos petrográficos efetuados em diques félsicos e máficos da região de Piratini, RS, mostram a existência de texturas porfirítica, glomeroporfirítica a esferulítica (félsicos), em matriz afanítica ou muito fina, e ofítica a sub-ofítica com intercrescimento mirmequítico (máficos). Estes corpos, com orientação dominante NW-SE e N-S, encontram-se encaixados em rochas graníticas do Batólito Pelotas. Os diques máficos possuem afinidade geoquímica alcalina e os félsicos, sub-alcalinas. Os primeiros são fortemente metaluminosos, com índice de saturação em alumina $(\mathrm{A} / \mathrm{CNK})$ entre 0,60 a 0,65 , e os últimos são fracamente metaluminosos a levemente peraluminosos, com A/CNK entre 0,75 e 1,2. Os diques máficos apresentam teores em $\mathrm{SiO}_{2}$ entre 44 a $48 \%$ e os diques félsicos, entre 67 e $75 \%$. Os diques máficos apresentam teores mais elevados em Ti, $\mathrm{Mg}, \mathrm{Ca}, \mathrm{Fe}, \mathrm{Mn}$ e P. O comportamento de elementos maiores e traço ( $\mathrm{Ti}, \mathrm{Fe}, \mathrm{Mn}, \mathrm{P}, \mathrm{Zr}, \mathrm{Sr}$ e, em menor importância, $\mathrm{Ca}$ e $\mathrm{Mg}$ ) reflete o fracionamento de minerais ferromagnesianos e plagioclásio no magma gerador. Em diagramas com razões de elementos traço $(\mathrm{Nb} / \mathrm{Ta}$ e U/Th) evidenciam-se efeitos de contaminação crustal dos magmas que deram original aos diques. Os ETR(n) mostram padrões próximos da horizontalidade para os ETR pesados, com razões $\mathrm{Tb} / \mathrm{Lu}(\mathrm{n})$ para os diques máficos entre 1,5 a 2,7 (diques félsicos: entre 1,6 a 2,5 ) e valores de Lu em torno de 0,3 a $0,6 \mathrm{ppm}$ (diques félsicos: entre 18 e $41 \mathrm{ppm}$ ). Os ETR leves mostram-se enriquecidos nos diques félsicos, com teores de La entre 73 a $155 \mathrm{ppm}$ (contra 18 e $41 \mathrm{ppm}$ ) e razões La/Sm entre 3,5 a 5,0.
\end{abstract}

Palavras-chaves: Batólito Pelotas, diques máficos e félsicos, petrografia, geoquímica.

INTRODUÇÃO São encontradas na região centro-sul do estado do Rio Grande do Sul, nos domínios do Batólito Pelotas e das Bacias do Camaquã e Santa Bárbara, ocorrências de rochas vulcânicas e sub-vulcânicas (ácidas a intermediárias e básicas), incluindo rochas piroclásticas diversas (tufos, ignimbritos, brechas etc.), na forma de diques, derrames e sills, associadas ou não a seqüências sedimentares, com várias designações locais (Riolitos Asperezas, Tufos e Ignimbritos Ana Dias, Formações Hilário, Membro Rodeio Velho e Acampamento Velho), que foram desenvolvidas entre o final do Neoproterozóico III e o Eopaleozóico (Wildner et al. 2002; Lima et al. 1995; Janikian et al. 2003; Fragoso Cesar et al. 1986; Almeida et al., 2000 dentre outros).

Coube a Figueiredo Filho \& Salgado (1964) a denominação de Riolitos Asperezas para a ocorrência de enxame de diques na região da Serra das Asperezas, situada a norte da de Pinheiro Machado. Neste mesmo trabalho, os autores advogam a existência de uma estreita ligação entre os diques félsicos e as rochas graníticas da região.

Posteriormente, outros autores reconhecem ocorrências de diques similares na região de Piratini e descrevem a existência de diques básicos e intermediários associados (Picada 1971; Ribeiro 1977; Gomes et al. 1990; Philipp et al. 1991; Philipp 1998, dentre outros).
Estes diques têm sido correlacionados na literatura com os Riolitos Asperezas da região de Pinheiro Machado e com as rochas sub-vulcânicas e vulcânicas ácidas (Tufos e Ignimbritos Ana Dias) do Platô do Taquarembó, sendo também incluídos por alguns autores na Suíte Dom Feliciano (Fragoso Cesar et al. 1984; Philipp 1998; Philipp \& Machado 2001; Wildner et al., 2002).

Dados geocronológicos $\mathrm{Rb} / \mathrm{Sr}$ disponíveis para os diques ácidos dos Riolitos Asperezas apontam idades de $560 \pm 12$ (Soliani Jr., 1986). Embora os recentes dados isotópicos U/Pb (Convencional e SHRIMP) e $\mathrm{Pb} / \mathrm{Pb}$ (evaporação) forneçam idades relativamente mais antigas para as rochas correlacionadas aos Riolitos Asperezas (ver Koster et al. 2001, Philipp et al. 2002), há a consenso entre os autores em considerá-los como vinculados à fase final do magmatismo granítico do Batólito Pelotas, notadamente com a Suíte Granítica Dom Feliciano.

O presente trabalho envolve a caracterização petrográfica e geoquímica (elementos maiores, menores, traços e terras raras) do enxame de diques félsicos e máficos associados ao Batólito Pelotas na região de Piratini, RS.

ARCABOUÇO TECTÔNICO REGIONAL Uma feição estrutural comum no Batólito Pelotas é a presença de zonas de cisalhamento dúctil a dúctil-rúptil, principalmente de alto ân-

1 - Pós-graduando do Programa de Geoquímica e Geotectônica do Instituto de Geociências da USP

2 - Instituto de Geociências da USP e Pesquisador do CNPq. Rua do Lago 562, CEP 05508-900, São Paulo, SP, e-mail: rmachado@usp.br

3 - Instituto de Geociências da UFRGS e Pesquisador do CNPq. Av. Bento Gonçalves, 9500, CEP 91540-000, Porto Alegre - RS, CP-15001, e-mail: ruy.philipp@ufrgs.br 


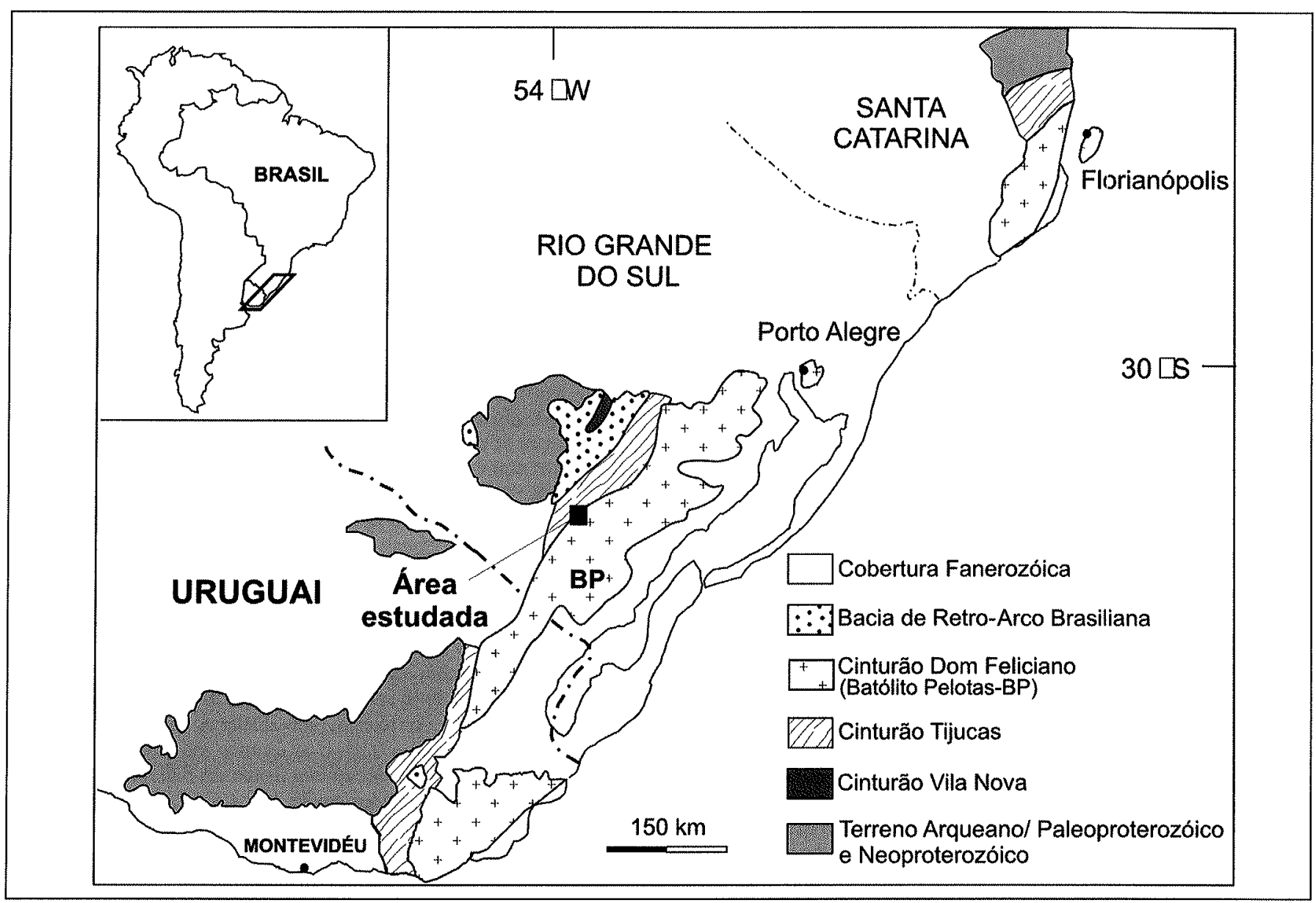

Figura 1. Mapa de localização da área estudada (modificado de Chemale et al. 2000).

gulo, que desempenharam um papel muito importante tanto na colocação das suítes graníticas do batólito, quanto na colocação dos diques a ele associados. Estas zonas de cisalhamento foram ativas desde o posicionamento das suítes graníticas mais antigas do batólito (Suíte Pinheiro Machado), com idades U/Pb (Convencional e SHRIMP) e $\mathrm{Pb} / \mathrm{Pb}$ (evaporação) entre 0,61 a 0,63 Ga (Babinski et al. 1997, Silva et al. 1999, Philipp et al. 2002), até o posicionamento das suítes mais novas, como a Suíte Dom Feliciano, cujas idades obtidas pelas mesmas metodologias, nos granitos Capão do Leão e Santana, forneceram valores entre 0,58 e 0,60 (Koster et al. 2001, Philipp et al. 2002).

Idades mais novas entre 0,53 e $0,54 \mathrm{Ga}$, obtidas pelo método $\mathrm{Ar} / \mathrm{Ar}$, em milonitos de zonas de cisalhamento que afetam rochas graníticas do batólito, foram atribuídas a um evento tectônico tardio ao de geração destas rochas, e interpretado como um evento de reativação tectônica, relacionado aparentemente com a tectônica extensional responsável pelo desenvolvimento da Bacia do Camaquã, situada à oeste do batólito (Philipp et al. 2003).

Estruturalmente nota-se, no domínio do batólito, a presença de zonas de cisalhamento rúpteis/dúcteis de alto ângulo NE-SW paralelas à zona de cisalhamento principal da região (Zona de Cisalhamento Dorsal de Canguçu - ZCDC), que limita as rochas graníticas do Batólito Pelotas das rochas metamórficas do Complexo Metamórfico Porongos. A movimentação principal da ZCDC tem sido caracterizada como sinistral (Fernandes et al. 1992, Philipp et al. 1993). Associadas a esta zona de cisalhamento, são descritas espessas faixas de milonitos (entre 6 e $7 \mathrm{~km}$ de largura) que se estendem do Rio Grande do Sul até o Uruguai. A ZCDC afeta tanto rochas das suítes graníticas do batólito, quanto às rochas mais antigas. Em várias regiões do batólito são descritos diques associados a zonas de cisalhamento dúcteis/rúpteis de alto ângulo, NNE-SSW, com movimentação dominante direcional sinistral (Frantz \& Remus 1986, Fernandes et al. 1992, Philip et al. 1993). Estes diques, com espessuras métricas e extensão de dezenas a centenas de metros, ocorrem na forma de enxames e encontram-se encaixados em rochas graníticas do Batólito Pelotas, com sua maior área de ocorrência sendo registrada nas regiões de Pinheiro Machado e Piratini.

GEOLOGIA DA REGIÃo DE PIRATINI A área estudada abrange em termos geográficos a região do município de Piratini (RS) e situa-se geologicamente no domínio do Batólito Pelotas, porção leste do Escudo Sul-rio-grandense (Fig.1).

A região de Piratini é caracterizada pela ocorrência de enxames de diques félsicos e máficos encaixados em rochas graníticas do Batólito Pelotas. Os diques são de natureza sub-vulcânica e encontram-se alojados ao longo de zonas de cisalhamento dúcteis/rúpteis de alto ângulo de direções dominantes próximas de NNE-SSW e N-S, com registros de movimentação direcional, oblíqua e normal. Os diques também cortam as rochas encaixantes dos granitos e ocorrem ao redor de corpos graníticos como Cerro do Sandi, Passo do Coutinho e Bela Vista (Gomes et al. 1991, Philipp et al. 1991).

$\mathrm{O}$ enxame de diques encontra-se afetado por zonas de cisalhamento subverticais, que promovem o encurvamento dos mesmos e deformação no estado sólido. Em mapa, nota-se também a existência de uma geometria curva no granito Bela Vista, junto à zona de falha à leste, de forma análoga à curvatura definida pelos diques, sugerindo colocação simultânea com a movimentação da falha. 


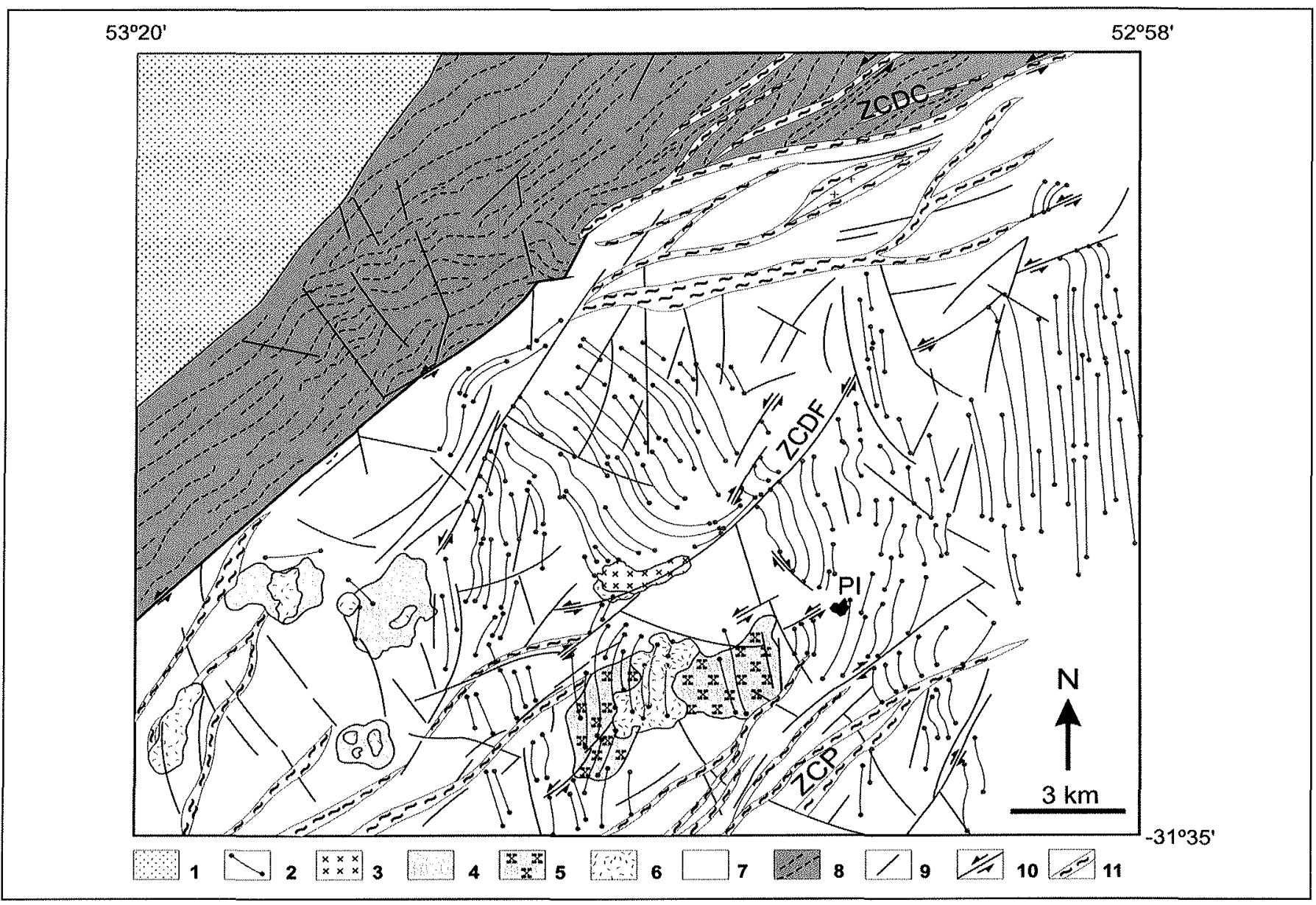

Figura 2. Mapa geológico da regiâa de Piratini, RS (modificado da CPRM 1999, Philipp et al. 2005). Legenda: 1- Bacia do Camaquã; 2-Diques máficos e félsicos; 3- Granito Bela Vista; 4-Granitos da Suite Dom Feliciano; 5 e 6 - Microgranitos e Granitos tipo Cerro do Sandi (Suite Dom Feliciano); 7- Monzogranitos porfiríticos (Suite Viamão); 8- Complexo Metamórfico Porongos; 9- Lineamentos; 10 e 11-Zonas de cisalhamento rúptil-dúctil e dúctil; ZCDC, ZCDF e ZCP - Zonas de Cisalhamento Dorsal do Canguçu, Dom Feliciano e Piratini; PI- Piratini

As rochas encaixantes apresentam composição sienogranítica a monzogranítica e granodiorítica, sendo relacionadas respectivamente as suites Viamão (SV), Dom Feliciano (SDF) e Pinheiro Machado (SPM).

Ocorrem também na região corpos graníticos subcirculares a ligeiramente alongados segundo as zonas de cisalhamento de direção NNE-SSW (Granitos Cerro do Sandi, Passo do Coutinho e Bela Vista). Estes corpos graníticos são cortados ou não por diques, sugerindo de forma análoga o mesmo tipo de controle estrutural durante sua colocação.

Os granodioritos são de cor cinza, granulação média a grossa e textura inequigranular, exibindo bandamento magmático caracterizado por schlieren milimétrico a centimétrico de biotita, de forma irregular e descontínuo.

Os monzogranitos são heterogranulares a porfiríticos, rosados, contendo megacristais euédricos de K-feldspato orientados e imersos numa matriz equigranular grossa à média $(4-8 \mathrm{~mm})$, composta por plagioclásio, K-feldspato, quartzo e biotita. Possuem estrutura de fluxo magmático definido pela orientação dimensional de megacristais tabulares de K-feldsapto, euédricos a subédricos, com limites retilíneos a lobados e zonamento marcado por trilhas concêntricas de inclusões de biotita, plagioclásio e minerais opacos. A biotita é intersticial e ocorre associada aos minerais opacos. São encontrados enclaves de composição sienogranítica e monzogranítica, arredondados a subarredondados, de dimensões centimétricas (15 a $40 \mathrm{~cm}$ ).
Os monzogranitos ocorrem como corpos alongados concordantes com as zonas de cisalhamento de alto ângulo NE-SW. Apresentam foliação magmática que transiciona muitas vezes para uma foliação no estado sólido para o interior destas zonas de cisalhamento, aparecendo aí rochas miloníticas de espessura métrica. Tais relações estruturais sugerem tratar-se de corpos de colocação sin a tardi-transcorrência.

Os sienogranitos são leucocráticos, rosados, granulação média (3 a $6 \mathrm{~mm})$ e textura equigranular. Os minerais essenciais são K-feldspato, plagioclásio, quartzo e biotita. O quartzo possui forma amebóide e a biotita é intersticial. Os sienogranitos caracterizam-se por formarem corpos circunscritos com grande incidência ao seu redor de diques félsicos e máficos, dentre os quais destacam-se os granitos Cerro do Sandi, Passo do Coutinho e Bela Vista (Gomes et al. 1991, Philipp et al. 1991 e 2002). Estes granitos são controlados por zonas de cisalhamento rúpteis/dúcteis de orientação geral $\mathrm{N} 30-60^{\circ} \mathrm{E}$, responsáveis também pela forma alongada dos mesmos.

Enxame de Diques Na região de Piratini ocorrem mais de duas centenas de diques félsicos e máficos, havendo o predomínio dos primeiros em relação aos últimos. Os diques máficos e félsicos apresentam duas direções principais: uma NW-SE e outra direção próxima de N-S. Cabe aqui novamente salientar que não foram observadas no campo relações temporais entre as duas direções de diques, tendo sido observadas apenas relações 


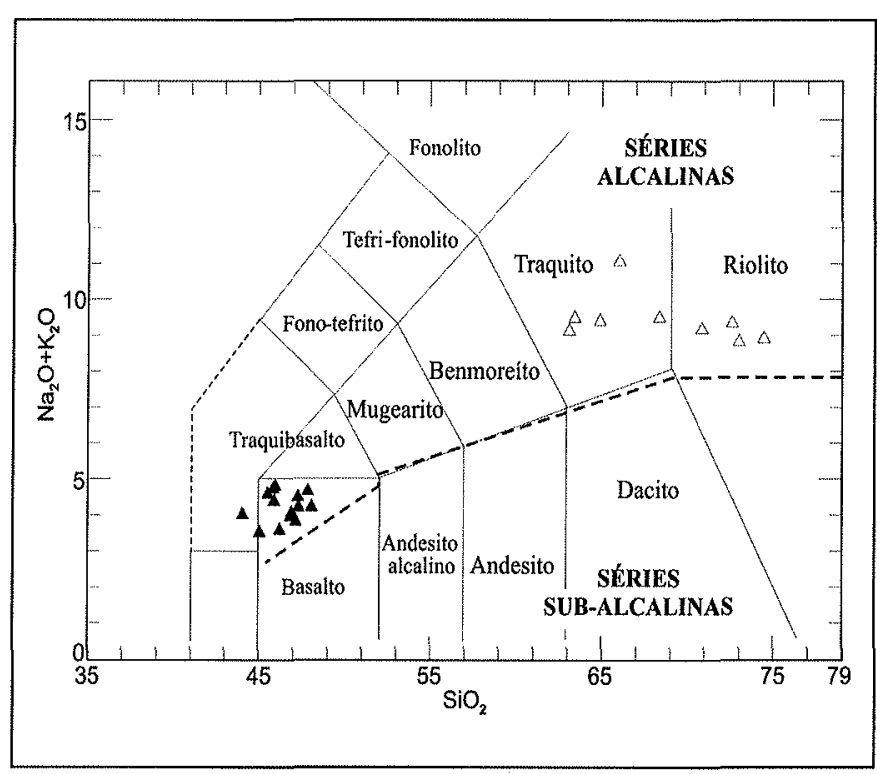

Figura 3. Diagrama de classificação $\mathrm{SiO} 2$ versus $\mathrm{Na} 2 \mathrm{O}+\mathrm{K} 2 \mathrm{O}$ (TAS -Le Bas et al. 1986) para os diques félsicos e máficos da região de Piratini, $R S$. A linha traacejada indica o limite entre as séries subalcalinas e alcalinas de Kuno (1968). Simbologia: triângulo vasado - diques félsicos; triângulo cheio - diques máficos.

de mistura física (mingling) de magmas entre os diques máficos e félsicos, sugerindo assim contemporaneidade entre eles. Os diques da região de Piratini são corpos tabulares, de espessura centimétrica a métrica ( $30 \mathrm{~cm}$ até 10 metros), mostrando contatos retos com os granitos encaixantes, sendo comum à ocorrência conjunta no mesmo afloramento dos dois tipos de diques. Os diques máficos são mais freqüente na região nordeste da área estudada. $\mathrm{O}$ estudo detalhado do enxame de diques nesta região permitiu a separação de dois grupos distintos, um de carater félsico e outro de caráter máfico, identificando-se composição mineralógica e feições texturais (observadas em microscopia) diferenciadas, entretanto, em ambos os tipos, observa-se que a matriz é maciça, afanítica/porfíritica, com granulação fina. $O$ mapa geológico da área estudada está representado na figura 2.

\section{PETROGRAFIA DOS DIQUES FÉLSICOS E MÁFICOS}

Os diques félsicos, quando não alterados, exibem cor róseaavermelhada. Macroscopicamente apresentam matriz afanítica e textura porfiritica, com até cerca de $10 \%$ em volume de fenocristais de feldspato alcalino e quartzo, geralmente este último bipiramidal, imersos em uma matriz fina.

Ao microscópio apresentam texturas porfirítica, glomeroporfirítica e esferulítica, com matriz muito fina e microcristalina. Os minerais essenciais são feldspato alcalino, plagioclásio e quartzo. Os minerais acessórios são plagioclásio $\left(\mathrm{An}_{5-10}\right.$ e $\mathrm{An}_{16-}$ ${ }_{20}$ ), minerais opacos, biotita, zircão, apatita e, mais raramente, titanita e anfibólio alterado. Ocorrem ainda caulinita, sericita clorita, mica branca, epídoto, carbonato, óxido de ferro, epídoto e fluorita como minerais de alteração.

O feldspato alcalino ocorre como fenocristal e como integrante da matriz. Os fenocristais são hipidiomórficos a xenomórficos e caracterizam-se como microclínio, ortoclásio e, mais raramente, como sanidina. Apresentam inclusões de zircão, minerais opacos, titanita e plagioclásio, e desenvolvem ao seu redor "franjas" com intercrescimento de quartzo e felspato alcalino, evidenciando textura granofírica. Ocorre também textura esferulítica, caracterizada por cristais de quartzo e feldspato alcalino dispostos ao redor de um núcleo constituído de agregados

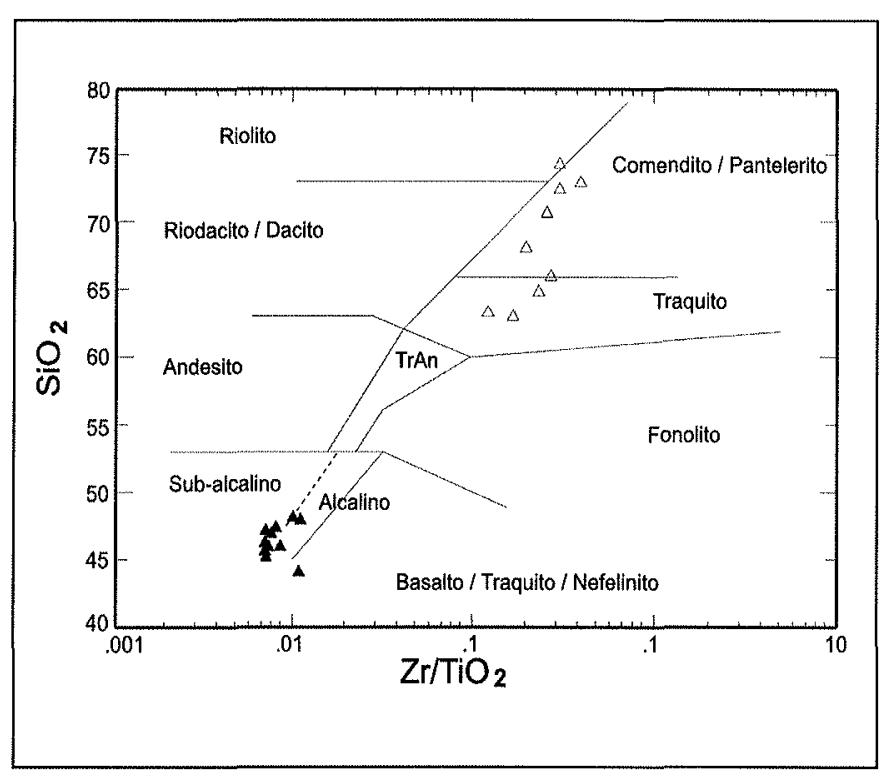

Figura 4. Diagrama de classificação SiO2 versus $\mathrm{Zr}$ ' TiO2*0.0001 (Winchester \& Floyd 1977) para os diques félsicos e máficos da região de Piratini, RS. A linha tracejada divide o campo dos basaltos alcalinos dos subalcalinos. Simbologia: Idem figura 3.

cristalinos de mesma composição.

O quartzo ocorre como fenocristal ( 2 a $4 \mathrm{~mm}$ ) e como integrante da matriz ou intersticial. Os primeiros são idiomórficos, límpidos, com limites retos, e encontram-se imersos numa matriz mais fina. Os cristais da matriz são subarredondados, limites lobados a serrilhados, exibindo extinção ondulante. Ocorrem associados com feldspato alcalino e plagioclásio, formando em geral uma matriz muito fina $(0,01$ a $0,03 \mathrm{~mm})$.

O plagioclásio ocorre na matriz como cristais idiomórficos, ripiformes, apresentando muitas vezes intercrescimento mirmequítico com quartzo e feldspato alcalino. Mostra franjas de composição albítica recristalizadas. A composição dominante é albita (An5-10) e oligoclásio (An16-20), com zonamento normal, onde o núcleo mostra-se mais cálcio do que a borda. Localmente, observa-se zonamento inverso.

Os diques máficos são mesocráticos, de cor cinza-esverdeada a preta, sendo comum a presença de veios milimétricos contendo sulfetos. Os minerais essenciais são plagioclásio e piroxênio, enquanto os minerais acessórios são quartzo, feldspato alcalino, apatita e titanita, ocorrendo ainda epídoto, anfibólio, magnetita e sulfetos. Os minerais de alteração são carbonato, clorita, sericita e mica branca.

Ao microscópio, predominam texturas sub-ofitica e intersertal. No primeiro caso, observam-se cristais tabulares de plagioclásio envolvidos parcialmente por cristais de piroxênio. No segundo, notam-se minúsculos cristais de quartzo entre cristais ripiformes de plagioclásio.

O plagioclásio ocorre na matriz e como fenocristal, com este último exibindo zonamento normal, inverso e oscilatório. Aquele possui composição albita $\left(A n_{3,6-3,2}\right)$ e este, andesina $\left(A n_{50-43}\right)$ e labradorita $\left(\mathrm{An}_{60-51}\right)$. Apresentam-se como cristais hipidiomórficos a xenomórficos e encontram-se em geral saussuritizados. São comuns cristais com geminação polissintética da albita.

O piroxênio ocorre como cristais xenomórficos e também de forma esqueletal. Mostra pleocroísmo verde-claro, levemente zonado, e envolve parcialmente os cristais de plagioclásio. De acordo com os dados de química mineral, possui composição da augita-diopsídio. 
Tabela 1. Análises quimicas de elementos maiores (\%) dos diques ácidos, básicos e granitos da região de Piratini, RS.

\begin{tabular}{|c|c|c|c|c|c|c|c|c|c|c|c|c|c|c|c|c|}
\hline Amostra & $\mathrm{SiO}_{2}$ & $\mathbf{A l}_{2} \mathbf{O}_{3}$ & $\mathrm{Fe}_{2} \mathrm{O}_{3}$ & MnO & $\mathrm{MgO}$ & $\mathrm{CaO}$ & $\mathrm{Na}_{2} \mathrm{O}$ & $\mathbf{K}_{2} \mathbf{O}$ & $\mathrm{TiO}_{2}$ & $\mathbf{P}_{2} \mathrm{O}_{5}$ & Total & $\mathbf{P F}$ & IGA & $\mathrm{mg} \#$ & A/NK & $\mathrm{A} / \mathrm{CNK}$ \\
\hline \multicolumn{17}{|l|}{ Félsicos } \\
\hline $\mathrm{RC}-16$ & 63,09 & 15,17 & 7,13 & 0,15 & 0,36 & 2,07 & 4,05 & 5,03 & 0,59 & 0,18 & 100,28 & 2,45 & 0,59 & 0,05 & 1,25 & $\overline{0,95}$ \\
\hline RC-20A & 63,41 & 14,79 & 6,46 & 0,15 & 0,96 & 2,58 & 4,54 & 4,89 & 0,68 & 0,11 & 100,14 & 1,58 & 0,64 & 0,13 & 1,16 & 0,85 \\
\hline RC-18B & 64,87 & 14,97 & 6,12 & 0,17 & 0,21 & 1,74 & 4,15 & 5,21 & 0,44 & 0,10 & 99,99 & 2,01 & 0,62 & 0,03 & 1,19 & 0,96 \\
\hline RC-18E & 72,57 & 14,17 & 2,29 & 0,06 & 0,02 & 0,68 & 4,32 & 4,99 & 0,11 & 0,02 & 100,16 & 0,94 & 0,57 & 0,01 & 1,13 & 1,03 \\
\hline RC-18F & 74,40 & 13,16 & 1,90 & 0,04 & 0,07 & 0,65 & 4,41 & 4,42 & 0,10 & 0,02 & 99,90 & 0,75 & 0,67 & 0,03 & 1,09 & 0,99 \\
\hline RC-52 & 70,81 & 13,54 & 3,31 & 0,08 & 0,03 & 0,95 & 4,23 & 4,87 & 0,20 & 0,02 & 98,95 & 0,88 & 0,67 & 0,01 & 1,10 & 0,97 \\
\hline RC-53 & 68,29 & 14,85 & 4,91 & 0,16 & 0,10 & 0,50 & 4,07 & 5,38 & 0,33 & 0,06 & 100,03 & 1,39 & 0,64 & 0,02 & 1,09 & 1,03 \\
\hline RC-55 & 73,00 & 13,16 & 2,90 & 0,04 & 0,09 & 0,82 & 4,39 & 4,41 & 0,18 & 0,02 & 100,10 & 1,09 & 0,67 & 0,03 & 1,05 & 0,97 \\
\hline $\mathrm{RC}-71$ & 66,00 & 16,47 & 3,62 & 0,09 & 0,17 & 0,57 & 5,52 & 5,48 & 0,34 & 0,07 & 99,28 & 0,94 & 0,67 & 0,04 & 1,16 & 1,08 \\
\hline \multicolumn{17}{|l|}{ Máficos } \\
\hline $\mathrm{RC}-8$ & 48,07 & 14,89 & 11,94 & 0,17 & 5,17 & 7,93 & 3,28 & 0,92 & 2,40 & 0,51 & 100,14 & 4,85 & 0,28 & 0,30 & 2,32 & 0,71 \\
\hline RC-9 & 46,87 & 15,08 & 13,60 & 0,19 & 5,42 & 8,33 & 2,99 & 1,07 & 3,10 & 0,58 & 99,37 & 2,13 & 0,27 & 0,28 & 2,48 & 0,71 \\
\hline $\mathrm{RC}-17$ & 47,30 & 15,46 & 12,86 & 0,21 & 5,83 & 7,69 & 3,15 & 1,36 & 2,45 & 0,49 & 99,04 & 2,23 & 0,29 & 0,31 & 2,32 & 0,75 \\
\hline $\mathrm{RC}-18 \mathrm{~A}$ & 47,11 & 15,17 & 12,49 & 0,18 & 6,14 & 8,72 & 2,87 & 0,95 & 2,50 & 0,45 & 98,76 & 2,17 & 0,25 & 0,33 & 2,63 & 0,70 \\
\hline RC-24 & 47,31 & 14,92 & 13,59 & 0,19 & 5,38 & 8,25 & 3,13 & 1,08 & 2,85 & 0,60 & 98,67 & 1,36 & 0,28 & 0,28 & 2,36 & 0,70 \\
\hline RC-51 & 47,86 & 15,36 & 12,07 & 0,18 & 5,55 & 7,89 & 3,11 & 1,56 & 2,46 & 0,53 & 98,77 & 2,19 & 0,35 & 0,31 & 2,25 & 0,72 \\
\hline RC-50 & 45,89 & 16,64 & 10,55 & 0,15 & 6,07 & 8,89 & 3,47 & 0,90 & 2,29 & 0,33 & 98,75 & 3,55 & 0,26 & 0,36 & 2,49 & 0,73 \\
\hline RC-59 & 46,18 & 15,53 & 12,48 & 0,18 & 7,06 & 9,10 & 2,91 & 0,71 & 2,48 & 0,42 & 99,23 & 2,17 & 0,23 & 0,36 & 2,79 & 0,70 \\
\hline RC-61 & 45,83 & 14,62 & 14,70 & 0,21 & 4,99 & 7,72 & 3,23 & 1,48 & 3,26 & 0,75 & 99,22 & 2,43 & 0,32 & 0,25 & 2,11 & 0,69 \\
\hline RC-67A & 45,49 & 15,48 & 12,13 & 0,18 & 6,02 & 8,63 & 3,11 & 1,47 & 2,80 & 0,68 & 98,59 & 2,61 & 0,29 & 0,33 & 2,30 & 0,69 \\
\hline RC-69 & 45,91 & 14,89 & 14,71 & 0,21 & 5,01 & 7,75 & 3,26 & 1,53 & 3,26 & 0,73 & 98,82 & 1,57 & 0,32 & 0,25 & 2,12 & 0,70 \\
\hline RC-84 & 46,84 & 15,76 & 11,06 & 0,17 & 6,62 & 10,09 & 2,93 & 1,00 & 2,25 & 0,47 & 98,86 & 1,67 & 0,25 & 0,37 & 2,67 & 0,65 \\
\hline RC-87 & 44,06 & 15,27 & 12,37 & 0,18 & 6,77 & 8,83 & 3,59 & 0,41 & 2,65 & 0,48 & 98,65 & 4,04 & 0,26 & 0,35 & 2,40 & 0,68 \\
\hline RC-83 & 45,09 & 14,43 & 11,67 & 0,17 & 8,44 & 10,23 & 2,88 & 0,64 & 2,16 & 0,28 & 99,03 & 3,04 & 0,24 & 0,42 & 2,66 & 0,60 \\
\hline \multicolumn{17}{|l|}{ Granitos } \\
\hline RC-30 & 75,10 & 13,02 & 1,44 & 0,06 & 0,30 & 1,03 & 3,52 & 4,81 & 0,24 & 0,06 & 100,05 & 0,41 & 0,64 & 0,17 & 1,18 & 1,01 \\
\hline RC-42 & 67,64 & 14,94 & 3,97 & 0,06 & 1,23 & 3,65 & 3,40 & 2,97 & 0,75 & 0,21 & 99,36 & 0,54 & 0,43 & 0,24 & 1,69 & 0,97 \\
\hline RC-35 & 67,16 & 15,76 & 4,05 & 0,07 & 1,12 & 3,21 & 3,69 & 3,58 & 0,67 & 0,22 & 99,52 & 0,51 & 0,46 & 0,22 & 1,48 & 0,96 \\
\hline
\end{tabular}

A biotita ocorre como lamelas isoladas ou em agregados associada com magnetita, sulfetos, titanita, restos de anfibólio, epídoto e zircão. Ocorre também interdigitada com piroxênio, numa clara relação de uma fase tardia.

GEOQUÍMICA Foram analisadas 26 amostras de rochas, sendo 9 de diques félsicos, 14 de diques máficos e 3 dos granitos encaixante (Tabelas 1 e 2). As amostras analisadas foram coletadas nos arredores da cidade de Piratini. Os dados analíticos foram obtidos no Laboratório ACTLABS - Ontário - Canadá. As amostras foram inicialmente britadas e pulverizadas em moinho de ágata. Os elementos maiores foram analisados por ICP (Inductively Coupled Plasma) e os elementos traços e terras raras foram analisados por Inductively Coupled Plasma Mass Spectrometry (ICP-MS). Em ambos os casos, a abertura da amostra é feita em meio ácido, utilizando-se $\mathrm{HF}$ ou $\mathrm{HNO}_{3}$. A fusão é necessária apenas no primeiro caso, sendo feita na presença de sais de lítio, metaborato ou tetraborato. São discutidos conjuntamente os dados geoquímicos dos diferentes elementos analisados (maiores, traços e terras raras) com base em diferentes tipos de diagramas de classificação, caracterização e discriminação de ambientes tectônicos disponíveis na literatura, assim como em diagramas de Harker e de terras raras normalizados, com objetivo de definir a geração e evolução do magmatismo relacionados aos diques e sua possível ligação com a fase final do magmatismo do Batólito de Pelotas.

Para a classificação e caracterização magmática dos diques estudados, utilizou-se o diagrama de Le Bas et al. (1986) e Winchester \& Floyd (1977) (Figs. 3 e 4). Ambos os diagramas acentuam a diferença composicional entre os diques. Este último permite separar também o campo de basaltos alcalinos dos subalcalinos. No diagrama da fig. 3, os diques félsicos apresentam 
Tabela 2. Análises químicas dos elementos traço e terras raras (ppm) dos diques ácidos, básicos e granitos encaixantes da região de Piratini, RS.

\begin{tabular}{|c|c|c|c|c|c|c|c|c|c|c|c|c|c|c|c|c|c|c|c|c|c|c|}
\hline Amostra & $\mathbf{B a}$ & $\mathbf{S r}$ & $\mathbf{Y}$ & $\mathbf{Z r}$ & Hf & $\mathbf{R b}$ & $\mathbf{T a}$ & Th & $\mathbf{L a}$ & $\mathbf{U}$ & $\mathrm{Ce}$ & Nd & $\mathrm{Sm}$ & $\mathbf{E u}$ & $\mathbf{T b}$ & $\mathbf{Y b}$ & Lu & $\mathbf{N b}$ & $\mathbf{N i}$ & $\mathbf{P b}$ & $\mathrm{Nb} / \mathrm{Ta}$ & U/Th \\
\hline \multicolumn{23}{|l|}{ Félsicos } \\
\hline$\overline{R C 16}$ & 1120 & 114 & 52 & 959 & 17,3 & 133 & 4 & 13 & 89,8 & 2,2 & 168 & 70 & 14,1 & 3,3 & 1,4 & 4,4 & 0,66 & 68,4 & $\mathrm{Nd}$ & 15 & 17,1 & 0,17 \\
\hline $\mathrm{RC}-20 \mathrm{~A}$ & 194 & 108 & 61 & 819 & 15,5 & 138 & 5 & 18,6 & 141 & 3,9 & 255 & 102 & 19 & 2,1 & 1,9 & 5,7 & 0,85 & 91,9 & 10 & 17 & 18,3 & 0,21 \\
\hline RC-18B & 668 & 91 & 55 & 997 & 16,9 & 167 & 5 & 15,7 & 100 & 3,2 & 185 & 76 & 15,3 & 2,4 & 1,5 & 5,0 & 0,76 & 85,3 & 1 & 11 & 17,0 & 0,20 \\
\hline $\mathrm{RC}-18 \mathrm{E}$ & 16 & 15 & 92 & 330 & 10,1 & 333 & 8 & 28,5 & 73,4 & 5,4 & 160 & 70 & 19,3 & 0,6 & 2,2 & 7,0 & 1,03 & 144 & 3 & 56 & 18,0 & 0,19 \\
\hline $\mathrm{RC}-18 \mathrm{~F}$ & 35 & 45 & 91 & 298 & 10,6 & 304 & 8 & 32,9 & 49,9 & 7,1 & 106 & 49 & 18,7 & 0,4 & 2,6 & 7,3 & 1,01 & 136 & 2 & 36 & 17,0 & 0,21 \\
\hline $\mathrm{RC}-52$ & 161 & 33 & 65 & 525 & 12,4 & 187 & 5 & 22,7 & 130 & 3,8 & 236 & 92 & 17,2 & 1,2 & 1,4 & 5,6 & 0,84 & 89,8 & 1 & 17 & 17,9 & 0,16 \\
\hline $\mathrm{RC}-53$ & 973 & 74 & 77 & 624 & 13,0 & 140 & 3 & 17,5 & 150 & 2,3 & 227 & 99 & 19,5 & 3,2 & 2,0 & 5,7 & 0,85 & 67,3 & $\mathrm{Nd}$ & 19 & 22,4 & 0,13 \\
\hline RC-55 & 121 & 20 & 122 & 712 & 19,4 & 144 & 8 & 29,5 & 155 & 3,8 & 277 & 109 & 22,7 & 0,7 & 2,7 & 9,7 & 1,49 & 141 & 2 & 25 & 17,6 & 0,13 \\
\hline $\mathrm{RC}-71$ & 469 & 49 & 49 & 912 & 14,7 & 126 & 4 & 10,6 & 80,4 & 2,7 & 148 & 55 & 10,6 & 1,7 & 1,2 & 4,8 & 0,74 & 77,0 & 3 & 15 & 19,2 & 0,25 \\
\hline \multicolumn{23}{|l|}{ Máficos } \\
\hline RC-8 & 512 & 582 & 29 & 240 & 4,9 & $\mathrm{Nd}$ & 3 & 2,5 & 34,2 & 1,2 & 61 & 30 & 7,4 & 2,3 & 0,9 & 2,4 & 0,38 & 26,0 & 19 & $\mathrm{Nd}$ & $\overline{8,6}$ & 0,48 \\
\hline RC-9 & 413 & 659 & 30 & 234 & 4,6 & $\mathrm{Nd}$ & 2 & 2,4 & 34,0 & $\mathrm{Nd}$ & 62 & 30 & 7,7 & 2,4 & 0,8 & 2,4 & 0,37 & 31,4 & 26 & $\mathrm{Nd}$ & 15,7 & - \\
\hline $\mathrm{RC}-17$ & 461 & 669 & 34 & 197 & 4,0 & 38 & Nd & 1,7 & 28,7 & 1,2 & 52 & 26 & 6,9 & 2,3 & 0,9 & 2,6 & 0,39 & 23,8 & 31 & $\mathrm{Nd}$ & - & 0,70 \\
\hline $\mathrm{RC}-18 \mathrm{~A}$ & 319 & 645 & 27 & 177 & 3,7 & $\mathrm{Nd}$ & 1 & 1,7 & 26,5 & $\mathrm{Nd}$ & 52 & 26 & 6,4 & 2,2 & 0,8 & 2,3 & 0,35 & 22,3 & 52 & $\mathrm{Nd}$ & 22,3 & - \\
\hline $\mathrm{RC}-24$ & 432 & 592 & 31 & 231 & 5,2 & $\mathrm{Nd}$ & 2 & 2,5 & 35,1 & $\mathrm{Nd}$ & 66 & 37 & 8,2 & 2,2 & 0,5 & 2,5 & 0,40 & 28,4 & 42 & $\mathrm{Nd}$ & 14,2 & - \\
\hline $\mathrm{RC}-51$ & 432 & 605 & 31 & 269 & 5,6 & 41 & 3 & 3,0 & 40,9 & 1,0 & 72 & 34 & 8,1 & 2,3 & 0,8 & 2,7 & 0,40 & 34,1 & 34 & $\mathrm{Nd}$ & 11,3 & 0,33 \\
\hline RC-50 & 212 & 567 & 24 & 169 & 3,5 & $\mathrm{Nd}$ & $\mathrm{Nd}$ & 1,2 & 19,0 & 0,8 & 36 & 21 & 5,2 & 1,7 & 0,6 & 1,9 & 0,29 & 16,2 & 37 & $\mathrm{Nd}$ & - & 0,67 \\
\hline RC-59 & 268 & 604 & 23 & 172 & 3,6 & $\mathrm{Nd}$ & 2 & 1,9 & 24,7 & 1,0 & 46 & 23 & 5,8 & 1,9 & 0,6 & 2,0 & 0,30 & 23,5 & 55 & $\mathrm{Nd}$ & 11,7 & 0,52 \\
\hline RC-61 & 720 & 593 & 35 & 282 & 5,6 & $\mathrm{Nd}$ & 2 & 3,1 & 40,5 & $\mathrm{Nd}$ & 74 & 41 & 9,1 & 3,0 & 1,1 & 2,9 & 0,43 & 30,5 & 28 & $\mathrm{Nd}$ & 15,2 & - \\
\hline $\mathrm{RC}-67 \mathrm{~A}$ & 392 & 736 & 24 & 194 & 4,3 & 35 & 3 & 2,6 & 34,7 & $\mathrm{Nd}$ & 64 & 35 & 7,7 & 2,6 & 0,7 & 1,7 & 0,26 & 40,7 & 28 & $\mathrm{Nd}$ & 13,5 & - \\
\hline RC-69 & 707 & 606 & 33 & 274 & 5,7 & $\mathrm{Nd}$ & 2 & 2,7 & 41,0 & $\mathrm{Nd}$ & 76 & 38 & 8,9 & 3,0 & 1,1 & 2,8 & 0,42 & 32,2 & 26 & $\mathrm{Nd}$ & 16,1 & - \\
\hline $\mathrm{RC}-84$ & 347 & 484 & 27 & 214 & 4,3 & 58 & $\mathrm{Nd}$ & 1,6 & 22,1 & $\mathrm{Nd}$ & 45 & 25 & 6,2 & 2,1 & 0,9 & 2,7 & 0,41 & 21,6 & 58 & $\mathrm{Nd}$ & - & - \\
\hline $\mathrm{RC}-87$ & 184 & 529 & 39 & 288 & 5,6 & $\mathrm{Nd}$ & $\mathrm{Nd}$ & 0,6 & 18,0 & $\mathrm{Nd}$ & 44 & 28 & 7,7 & 2,5 & 0,9 & 3,7 & 0,59 & 12,1 & 68 & $\mathrm{Nd}$ & - & - \\
\hline $\mathrm{RC}-83$ & 337 & 512 & 24 & 152 & 3,3 & $\mathrm{Nd}$ & 2 & 1,0 & 15,0 & 0,7 & 30 & 18 & 4,9 & 1,8 & 0,7 & 2,2 & 0,34 & 16,0 & 128 & $\mathrm{Nd}$ & 8,0 & 0,70 \\
\hline \multicolumn{23}{|l|}{ Granitos } \\
\hline RC-30 & 564 & 125 & 36 & 224 & 4,9 & 160 & & 12,7 & 66,6 & 1,9 & 111 & 41 & 8,4 & 1,1 & 0,8 & 3,1 & 0,47 & 18,2 & 2 & 28 & 18,2 & 0,15 \\
\hline RC- 42 & 904 & 391 & 28 & 225 & 4,6 & 147 & & 11,9 & 31,6 & 6,3 & 62 & 34 & 8,3 & 1,7 & 1,0 & 2,3 & 0,34 & 17,9 & 6 & 15 & 8,95 & 0,53 \\
\hline $\mathrm{RC}-35$ & 1726 & 588 & 12 & 314 & 7,1 & 136 & 1 & 7,2 & 59,8 & $\mathrm{Nd}$ & 96 & 44 & 6,3 & 1,8 & $\mathrm{Nd}$ & 1,3 & 0,20 & 15,6 & 4 & 21 & 15,6 & - \\
\hline \multicolumn{23}{|c|}{ Nd: Não determinado } \\
\hline
\end{tabular}

composição riolítica com subordinações traquítica, enquanto os diques máficos apresentam composição de basalto. No diagrama de fig. 4, os diques félsicos ocupam os campos traquito, comendito/pantalerito e riolito, enquanto que os diques máficos situam-se no limite do campo dos basaltos alcalinos e subalcalinos, caracterizando um trend com tendência alcalina. $\mathrm{O}$ índice de saturação em alumina (ISA), também referido índice $\mathrm{A} / \mathrm{CNK}$ por alguns autores (ver Chappell \& White 1992), que traduz a razão molecular $\mathrm{Al}_{2} \mathrm{O}_{3} / \mathrm{CaO}+\mathrm{Na}_{2} \mathrm{O}+\mathrm{K}_{2} 0$, apresenta valores com intervalos distintos para os diques estudados. As amostras dos diques máficos possuem caráter fortemente metaluminoso, com índice $\mathrm{A} / \mathrm{CNK}$ entre 0,60 a 0,65 , enquanto os diques félsicos e os granitos possuem caráter fracamente metaluminoso a levemente peraluminoso, com índice $\mathrm{A} / \mathrm{CNK}$, respectivamente, entre 0,75 a 1,2 e entre 0,96 a 1,02, já bastante próximo do campo peralcalino. $\mathrm{O}$ índice $\mathrm{A} / \mathrm{NK}\left(\mathrm{Al}_{2} \mathrm{O}_{3} / \mathrm{Na}_{2} \mathrm{O}+\mathrm{K}_{2} \mathrm{O}\right)$ para os diques máficos situa-se entre 2,1 a 2,8, para os diques félsicos, entre 1,1 a 1,2, e para os granitos, entre 1,2 e 1,5. Este comportamento para os riolitos e granitos é influenciado principalmente pelos valores relativamente elevados em $\mathrm{Na}_{2} \mathrm{O}$ (entre 4,0 e 5,5\%) e $\mathrm{K}_{2} \mathrm{O}$ (entre
2,9 e 5,4\%). Por outro lado, os valores baixos exibidos por estes elementos nos diques máficos $\left(\mathrm{Na}_{2} \mathrm{O}\right.$, entre 2,8 e 3,5\%;

$\mathrm{K}_{2} \mathrm{O}$, entre 0,4 e $1,5 \%$ ) refletem seu caráter fortemente metaluminoso.

Nos diques máficos, os teores em $\mathrm{SiO}_{2}$ variam entre 44,0 a $48,0(\%)$, enquanto nos diques félsicos variam entre 63,0 a $74,4(\%)$, mostrando assim a existência de magmatismo bimodal com um gap composicional em $\mathrm{SiO}_{2}$ no intervalo de 48,0 a $63,0(\%)$. Os granitos apresentam conteúdos $\mathrm{em} \mathrm{SiO}_{2}$ entre 67,0 a 75,0 (\%). Os diques máficos, em relação aos diques félsicos e granitos, apresentam teores mais elevados em $\mathrm{Ti}, \mathrm{Mg}, \mathrm{Ca}, \mathrm{Fe}$, Mn e P (Fig. 5). Nestes últimos (granitos e diques félsicos) observa-se de maneira geral uma boa correlação linear de alguns elementos com o índice de diferenciação utilizado $\left(\mathrm{SiO}_{2}\right)$, ocorrendo durante a evolução um decréscimo de $\mathrm{Ti}, \mathrm{Fe}, \mathrm{Mn}, \mathrm{P} \mathrm{Zr}$ e $\mathrm{Sr}$, relativamente de $\mathrm{Mg}$ e $\mathrm{Ca}$, com aumento dos teores de $\mathrm{Ba}$ $\mathrm{Y}$ e $\mathrm{Nb}$, e comportamento mais ou menos constante de $\mathrm{Na}$ e $\mathrm{Rb}$ (Fig 5). O K comporta-se no início da evolução como elemento incompatível - até teores de cerca de $67 \% \mathrm{em} \mathrm{SiO}_{2}$ - e depois como elemento compatível. 


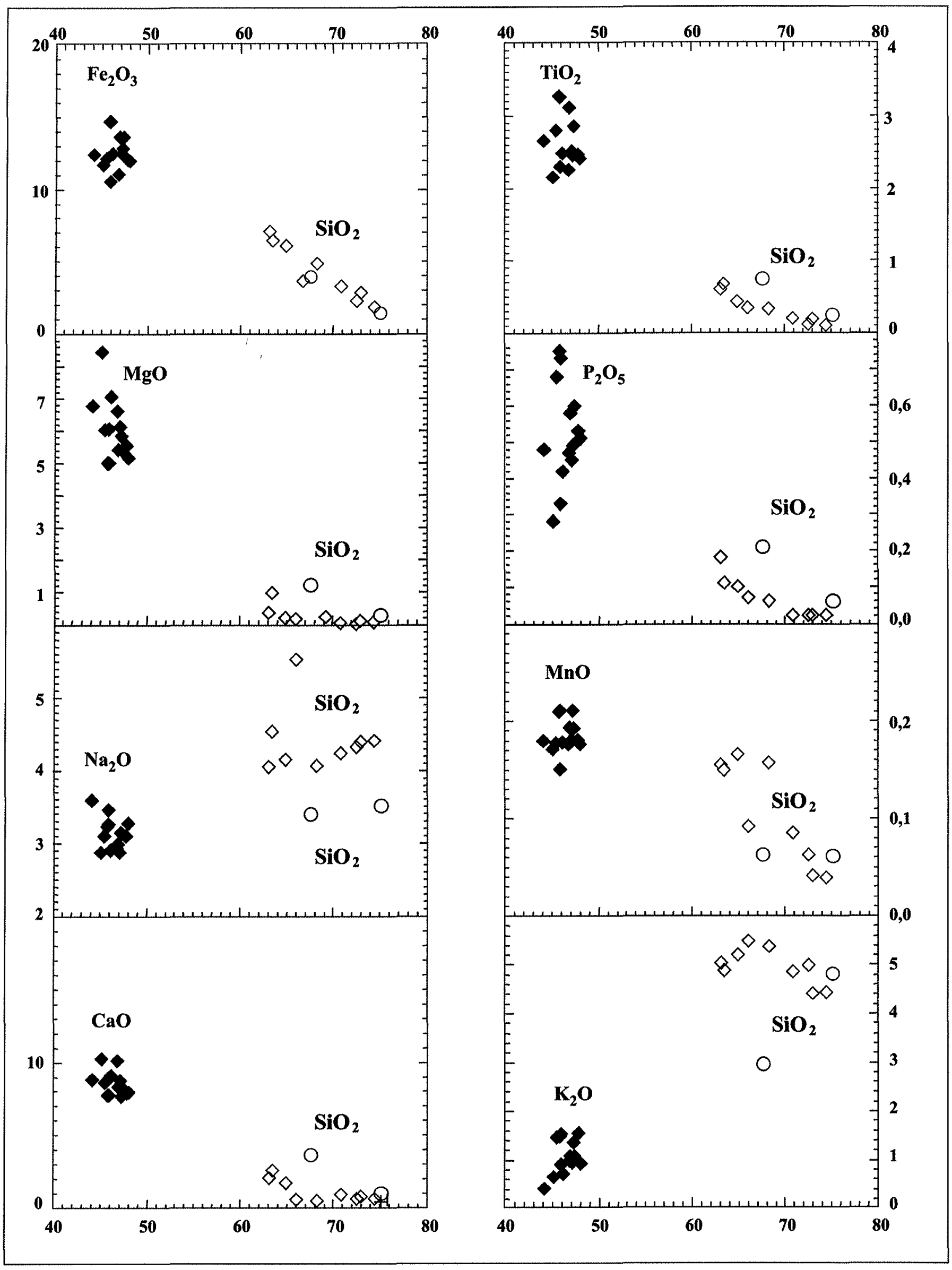

Figura 5. Diagramas de Harker mostrando as principais variações entre os elementos maiores e silica (\%) para o conjunto dos diques félsicos e máficos e granitos encaixantes. Simbologia: losângulo cheio - diques máficos; losângulo vasado - diques félsicos; círculo vasado - granitos encaixantes. 


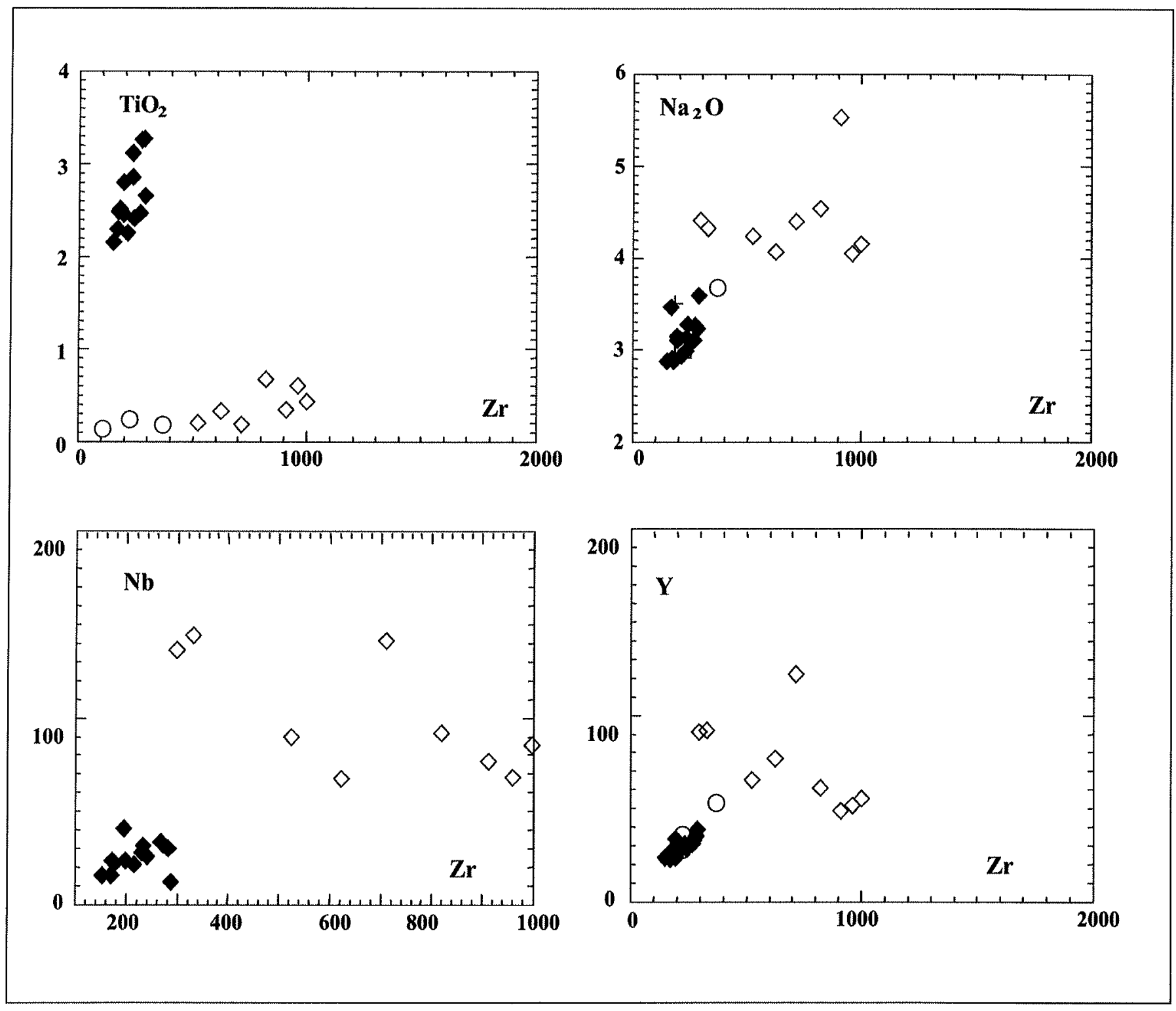

Figura 6. Diagramas binários de variação de Zr (ppm) versus elementos maiores (\%) e traço (ppm) para os diques félsicos e máfcos e granitos encaixantes da região de Piratini, RS. Simbologia: Idem figura 3

Com base na relação $\mathrm{MgO} /\left(\mathrm{MgO}+\mathrm{Fe}_{2} \mathrm{O}_{3}\right) 100(\%)$, os diques félsicos apresentam valores de $\mathrm{mg \#}$ entre 0,01 a 0,05 , os diques máficos, entre 0,25 a 0,42, e os granitos, entre 0,24 a 0,17 .

A utilização de diagramas com $\mathrm{Zr}$ como parâmetro de referência, em relação a outros elementos $\left(\mathrm{TiO}_{2}, \mathrm{Na}_{2} \mathrm{O}, \mathrm{Nb}\right.$ e Y), conforme sugerido por Leat et al. (1986) e Wilson (1989 e 1993), mostra comportamento contrastante entre as amostras dos diques máficos e félsicos, ressaltando assim as diferenças entre eles (Fig. 6).

O contraste do comportamento geoquímico entre os diques estudados é também evidenciado pelas razões envolvendo elementos traços $\left(\mathrm{Nb} / \mathrm{Ta}\right.$ e U/Th) versus elementos maiores ( $\mathrm{SiO}_{2}$ e $\mathrm{P}_{2} \mathrm{O}_{5}$ ) e também entre elementos traços (Th versus $\mathrm{U}$ ) (Fig. 7). Apenas o último diagrama (U vs.Th) apresenta uma correlação positiva clara para os dois tipos de diques. Nota-se ainda para os diques básicos um descréscimo na razão U/Th versus $\mathrm{SiO}_{2}$ e um aumento na razão $\mathrm{Nb} / \mathrm{Ta}$ versus $\mathrm{P}_{2} \mathrm{O}_{5}$ (Fig. 7), sugerindo para os mesmos de efeitos de contaminação crustal dos magmas seus predecessores.

As amostras de basaltos (diques máficos) apresentam um conjunto homogêneo com relação ao conteúdo de ETR (Fig. 8).
A distribuição dos $\mathrm{ETR}_{(\mathrm{n})}$ gera padrões próximos da horizontalidade para os ETR pesados, com razões $\mathrm{Tb} / \mathrm{Lu}_{(\mathrm{n})}$ da ordem de 1,5 a 2,7 e valores de $\mathrm{Lu}$ em torno de 0,3 a $0,6 \mathrm{ppm}$. Os ETR leves mostram-se enriquecidos, com teores de La situados entre $18 \mathrm{e}$ $41 \mathrm{ppm}$ e razões $\mathrm{La} / \mathrm{Sm}$ entre 3,5 a 5,0. O comportamento do $\mathrm{Eu}$ é caracterizado pela presença de anomalias levemente positivas pouco significativas, semelhantes ao comportamento descrito para basaltos alcalinos associados a comenditos-panteleritos de associações bimodais metaluminosas e peralcalinas encontradas em outras regiões do mundo (Civetta et al. 1998).

Os padrões de ETR dos granitos encaixantes são muito similares aos dos diques félsicos, exibindo forte anomalia negativa de Eu e mesmo comportamento de ETR leves. Nota-se, entretanto, conteúdos ligeiramente mais elevados nos ETR pesados nos diques félsicos (Figs. 8A,B e C).

Os ETR mostram padrões próximos da horizontalidade, com razões $\mathrm{Tb} / \mathrm{Lu}_{(\mathrm{n})}$ da ordem de 1,6 a 2,5 e valores de $\mathrm{Lu}$ entre 0,74 a $1,76 \mathrm{ppm}$ (diques félsicos) e entre 0,34 a $0,74 \mathrm{ppm}$ (granitos). Os ETR leves, com teores de La entre 73 a 155 ppm (diques félsicos) e entre 31 a $106 \mathrm{ppm}$ (granitos), mostram-se enriquecidos. As razões $\mathrm{La} / \mathrm{Sm}$ situam-se entre 4 e 6 . Observa- 


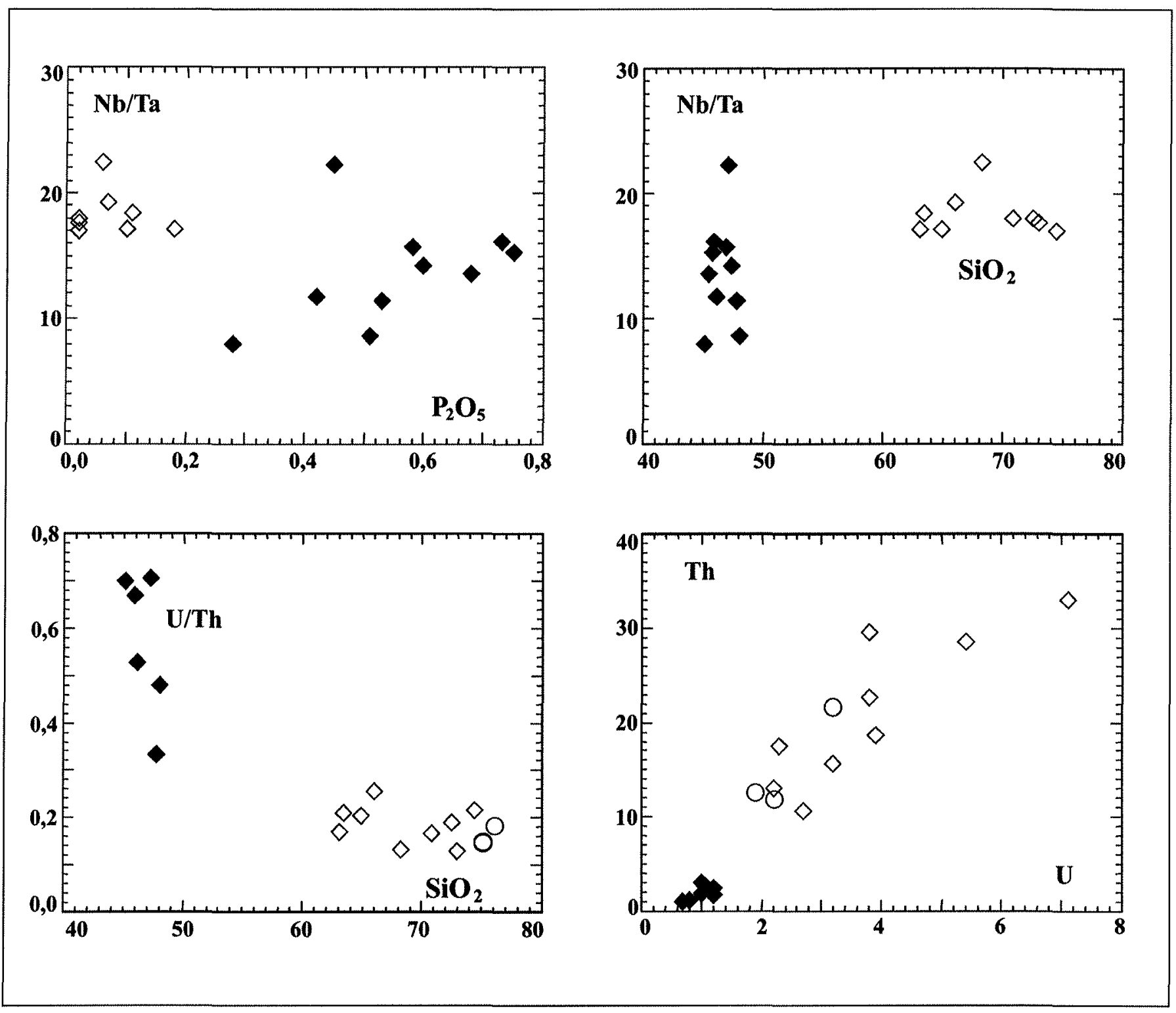

Figura 7. Diagramas $\mathrm{SiO}_{2}, \mathrm{P}_{2} \mathrm{O}_{5}(\%)$ e U versus razões $\mathrm{Nb} / \mathrm{Ta}$, U/Th (ppm) e Th (Black et al. 1997) para os diques félsicos e máficos e granitos encaixantes da região de Piratini, RS. Simbologia: Idem figura 3

se uma diminuição significativa nos teores de ETR leves para os diques félsicos mais ricos em $\mathrm{SiO}_{2} . \mathrm{O}$ comportamento do Eu é caracterizado pela presença de anomalias negativas, que aumentam acentuadamente nos termos mais diferenciados. Os padrões de ETR dos diques félsicos são semelhantes aos encontrados em associações comendíticas descritas em diferentes partes do mundo. Nestas regiões, os autores propõem que a assinatura dos ETR esteja relacionada aos processos de fracionamento mineral, principalmente de feldspatos (Parker, 1983, Civetta et al. 1998).

No diagrama discriminante $2 \mathrm{Nb}-\mathrm{Zr} / 4-\mathrm{Y}$ de ambiente tectônico para rochas basálticas (Meschede 1986) (Fig. 9), as amostras dos diques máficos ocupam os campos AI e AII de basaltos alcalinos intra-placas.

DISCUSSÃO E CONCLUSÕES A distribuição dos dados analíticos posição das amostras estudadas de Piratini nos diagramas de classificação de rochas vulcânicas (Le Bas et al. 1986) indica o caráter dominante alcalino para os diques félsicos e máficos e ambos os tipos se situam no campo das séries alcalinas acima da linha divisória com as séries sub-alcalinas de Kuno
(1968) (Fig. 3). No diagrama de Winchester \& Floyd (1977) (Fig. 4), os diques máficos ocupam o limite dos campos subalcalino e alcalinos, formando um trend de tendência alcalina. Entretanto os diques félsicos ocupam os campos dos traquitos, pantalleritos e comenditos, com as amostras formando um trend próximo a linha de divisória, indicando uma progressiva diferenciação do magma fonte com aumento das razões $\mathrm{Zr} / \mathrm{TiO}_{2}$ (Winchester \& Floyd, 1977). No diagrama da figura 10, $\mathrm{FeO}_{1}$ versus $\mathrm{Al}_{2} \mathrm{O}_{3}$, as amostras dos diques félsicos apresentam conteúdos compatíveis com rochas do tipo comenditos, enquanto as amostras dos diques máficos ocupam o campo dos pantalleritos (Le Maître 1989).

Os diques félsicos apresentam índice de saturação em alumina (A/CNK) muito próximo do campo das rochas peralcalinas, salientando assim a importância dos álcalis na caracterização do magma que deu origem a estas rochas. Os valores de mg\# evidenciam claramente o maior grau de evolução dos diques fél$\operatorname{sicos}(0,01$ a 0,05$)$, em relação aos diques máficos $(0,25$ a 0,42$)$, com os granitos $(0,17$ a 0,24$)$ apresentando valores mais próximos destes últimos. Observa-se que a diferenciação nos diques máficos é acompanhada pelo aumento de $\mathrm{K}, \mathrm{P}$ e Ba, com forte 


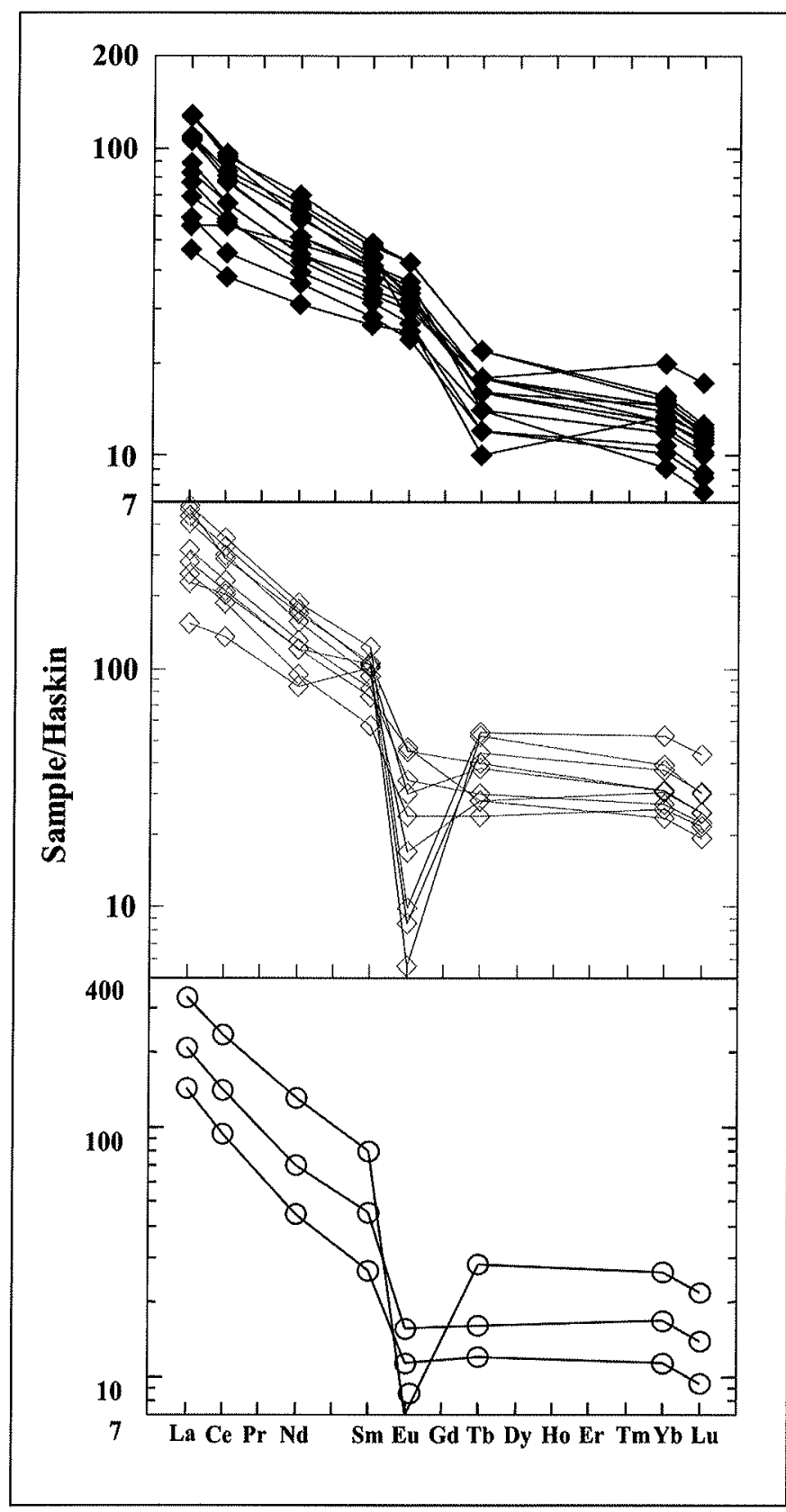

Figura 8. Padrões de elementos terras raras normalizados pelo condrito de Haskin et al. (1984) para os diques máficos $(A)$, diques félsicos $(B)$ e rochas graníticas encaixantes $(C)$ do Batólito Pelotas na região de Piratini, RS.

decréscimo em $\mathrm{Mg}$, Ti e $\mathrm{Fe}$, mostrando o efeito da cristalização dos minerais ferromagnesianos (Wilson 1986).

Os padrões de ETR muito semelhantes exibidos pelos diques máficos indicam um conjunto muito homogêneo das amostras, sugerindo uma forte similaridade do material fonte e dos processos magmáticos que deram origem a estas rochas. Os ETR dos diques félsicos e granitos representam um conjunto relativamente homogêneo com relação aos conteúdos destes elementos, mostrando conteúdos mais acentuados de ETR leves, anomalias fortemente negativas de Eu e valores muito baixos de ETR pesados.

O comportamento diferente dos elementos (maiores e traços) durante o processo de evolução magmática reforça assim as diferenças assinaladas entre os magmas que deram origem aos diques máficos e félsicos. Estas diferenças de comportamento se acentuam quando se utiliza nos diagramas $\mathrm{Zr}$ como parâmetro

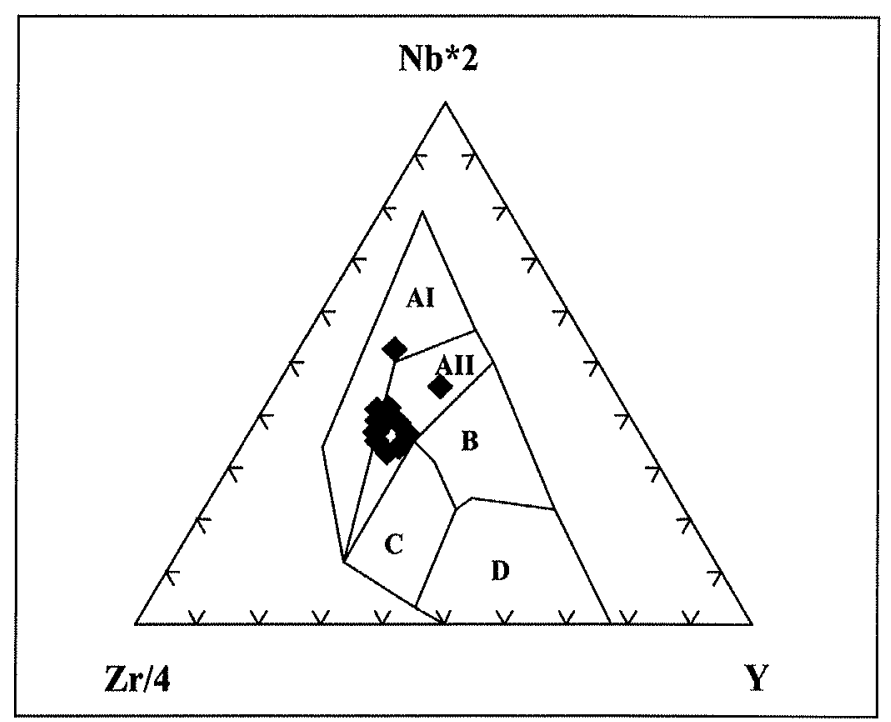

Figura 9. Diagrama discriminante de Meschede (1986) com os diques máficos da região de Piratini, RS. Legenda: AI e AII = Basalto Alcalino Intra-placa; $C=$ Basalto Toleítico Intraplaca; $B=$ PMORB; $D=N M O R B ; C-D=$ Basalto de Arco Vulcânico

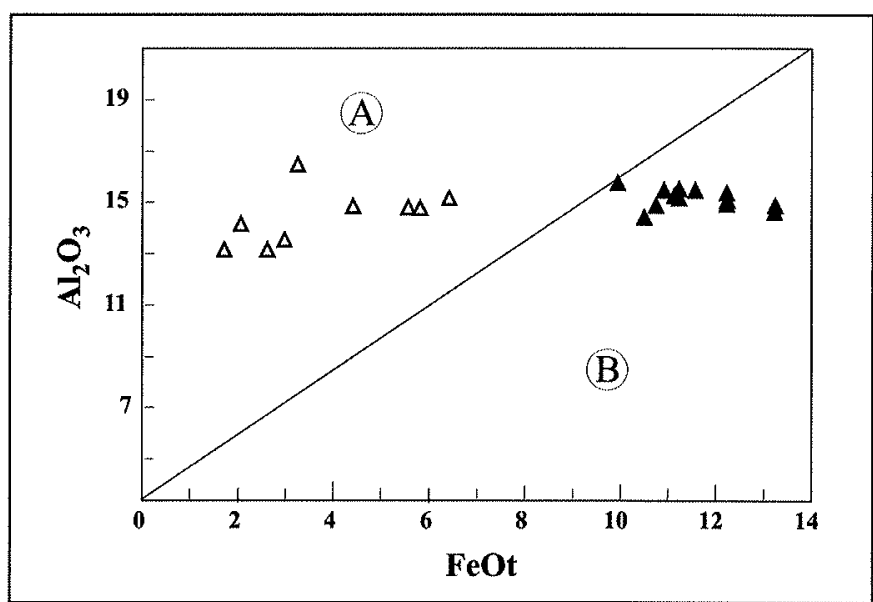

Figura 10. Diagrama $\mathrm{Al}_{2} \mathrm{O}_{3}$ vs. FeOt de MacDonald (1974) contendo diques félsicos e máficos da região de Piratini, RS. Simbologia: triângulo vasado - diques félsicos; triângulo cheio- diques máfico; $A$-comenditos, traquitos ou riolitos comenditicos; $B$ Pantalleritos, traquitos ou riolitos pantalleríticos.

de referência em relação a outros elementos.

O posicionamento das amostras estudadas nos diagramas de discriminação de ambiente tectônico de Meschede (1986) e Pearce et al. (1984) (este último não aqui apresentado) sugere que o magmatismo dos diques félsicos e máficos da região de Piratini foi gerado em condições de ambiente intra-placa, sendo isto também compatível com os dados de campo e geocronológicos. Estes aspectos são reforçados pelas evidências de contemporaneidade entre os dois tipos de magmatismo e pelo seu caráter tardio em relação às suítes graníticas mais jovens do Batólito Pelotas, cuja formação tem sido relacionado aos estágios tardi a pós-colisional do Ciclo Brasiliano (Bitencourt \& Nardi 1993 e 2000, Philipp et al. 2002).

Embora não seja comum a ocorrência de associações de rochas de suítes alcalinas e cálcio-alcalinas, registros deste tipo de 
associação têm sido referidos nas ilhas de Granada, Antilhas e México (Arculus \& Curran 1972). Nas Ilhas Granada, os basaltos alcalinos sub-saturados em sílica encontram-se associados com andesitos e dacitos cálcio-alcalinos. Os seus conteúdos em sílica $(44-47 \%)$ são os mesmos dos basaltos de Piratini (44 - 48\%) e apresentam também teores relativamente altos em álcalis (principalmente $\mathrm{Na}_{2} \mathrm{O}$ ). Os diques félsicos de Piratini (RS) mostram semelhança geoquímica com os riolitos hipabissais da região de Santuário (RS), sobretudo com relação aos conteúdos de elementos maiores (ambos ocupam o campo dos comenditos) e nos padrões dos ETR (Matos et al. 2002).

A presença de magmatismo bimodal na região de Piratini (RS) pode ser correlacionada com outras manifestações semelhantes no Escudo Sul-rio-grandense, a exemplo do que ocorre no Platô do Taquarembó (Wildner et al. 2002). Para os autores, as rochas vulcânicas e plutônicas félsicas foram derivadas de um mesmo magma básico a partir de processos de cristalização fracionada ocorrido em ambiente intra-placa pós-colisional. Este mesmo modelo petrogenético talvez possa ser aplicado para as rochas da região de Piratini. Contudo, a ausência de dados isotópicos de Sr e Nd torna-se dificil discutir com segurança a gênese do magmatismo gerador dessas rochas.

Agradecimentos Os autores agradecem à FAPESP (Proc. 99/10207-2), pelo suporte financeiro que permitiu a realização dos trabalhos de campo, ao CNPq (Proc. 300423/82-9, de R. Machado), pela concessão de uma bolsa de Produtividade em Pesquisa, e a CAPES (Celi Zanon), pela concessão de uma bolsa de doutorado. Os autores agradecem também aos revisores da $\mathrm{RBG}$ pelas sugestões ao manuscrito.

\section{Referências}

Arculus R. J. \& Curran, E. B. 1972 - The genesis of the calc-alkaline rock suite. Earth Planet. Sci., 15, 255-262.

Babinski M., Chemale Jr. F., Van Schmus W. R., Hartmann L. A., Silva L. C. 1997. U-Pb and Sm-Nd geochronology of the Neoproterozoic Granitic-Gneissic Dom Feliciano Belt, Southern Brazil. J. South Amer: Earth Sci., 10:263-274.

Baker P. E. 1982 - Evolution and classification of orogenic volcanic rocks.

Bitencourt M. F. \& Nardi L. S. V. 1993. Late to pos-collisional Brasiliano Magmatism in the Southernmost Brazil. An. Acad. Bras. Ciênc., 65: 3-16.

Bitencourt M. F. \& Nardi, L. V. S., 2000. Tectonic setting and sources of magmatism related to the Southern Brazilian Shear Belt. Rev. Bras, Geoc., 30:184-187.

Black S., Macdonald R., Kelly M. R. 1997. Crustal origin for peralkaline rhyolites from Kenya: eviedence from U-Series Disequilibria and Th-Isotopes. J. Petrol. 38: 277-297.

Chemale Jr. F. 2000. Evolução Geológica do Estado Sul-rio-grandense. In: Holz. M.; De Ros, L. F.(eds) Geologia do Rio Grande do Sul. Porto Alegre. CIGO- EFRGS, pp.:13-52.

Civetta L., D’Antônio M., Orsi, G., Tilton G. R. 1998. The geochemistry of volcanic rocks from Pantelleria Island, Silicy, Channel: petrogenesis and characteristics of the mantle source region. J. Petrol. 39: 1453-1491.

Cox K. G., Bell, J. D., Pankhurst R. J. 1979. The interpretation for igneous rocks. George Allen \& Unwin, London, 450p.

Irvigne T. N. \& Baragar W. R. A. 1971. A guide to the chemical classification of the common volcanic rocks. Can. J. Earth Sci., 8 : $523-548$.

Fernandes L. A., Tommasi A., Porcher C. C. 1992a. Deformation patterns in the southern Brazilian branch of Dom feliciano Belt; a reappraisal. J. South Amer: Earth Sci., 5(1): 77-96.

Figueiredo M.C.H., Fragoso Cesar A.R.S., Kronberg B.L.1990. Litogeoquímica das principais unidades do Batólito Pelotas no Rio Grande do Sul. In: SBG, Congr. Bras. Geol., 36, Natal, Anais, 4:1623-1738.

Fragoso-Cesar A. R. S., Figueiredo M. C. H., Soliani E.; Faccini U. F. 1986. O Batólito Pelotas (Proterozóico Superior/Eo-Paleozóico) no Escudo do Rio Grande do Sul. In: CBG, Congr. Bras. Geol., 34, Goiânia, 3:1322-1343.

Fragoso-Cesar A. R. S. \& Soliani Jr. E. 1984 . Compartimentação tectônica do Crtón do Rio de La Plata. In: CBG, Congr. Bras. Geol., 33, Rio de Janeiro, Anais, 5: 2426-2434,.

Frantz, J. C.; Lima, E. F.; Naumann, M. 1984. Contribuição a geologia de Encruzilhada do Sul - RS. In: SBG, Congr. Bras. Geol, 33, Rio de Janeiro, Anais, 5: 2407-2416.

Frantz J. C. \& Remus M. V.D. 1986. Geologia da região de CanguçuTorrinhas, RS: caracterização petrográfica, estrutural e estratigráfica. In: SBG, Congr. Bras. Geol., 34, Goiânia, Anais, 2:931-947.

Gomes M.E.B. 1990. Petrologia do Granito Arroio Moinho, Canguçu (RS): geoquímica e deformação. Instituto de Geociências, Universidade Federal do Rio Grande do Sul, Porto Alegre. Dissertação de Mestrado, 199p.

Gomes M. E. B.; Almeida D. P. M.; Philipp R. P., Pintaúde D. A. 1991. Caracterização mineralógica e geoquímica do granito Cerro do Sandi, Piratini-RS. Acta Geol. Leopoldensia, 14:123-144.

Haskin L. A., Haskin M.A., Frey F.A, Wildemann, T.R. 1968. Relative and absolute terrestrial abundances of the rare earts. $I n:$ I.H. Archeans (Eds.) Origin and distribution of the elements. Oxford, Pergamom, pp.: 889-912.

Janikian L., Almeida R.P., Fragoso-Cesar A.R.S., Fambrini G.L. 2003. Redefinição do Grupo Bom Jardim (Neoproterozóico III) em sua Área-Tipo: litoestratigrafia, evolução paleoambiental e contexto tectônico. Rev. Bras. Geoc., 33 (4): 347-360.

Koester E., Soliani Jr., E., Leite, J.A.D., Hartmann L.A., Fernandes L.A.D., McNaughton N.J., Santos J.O.S., Oliveira L.D. 2001. SHRIMP U-Pb age for the emplacement of the Santana Granite and reactivation of the Porto Alegre Suture, southern Brazil. J. South Amer: Earth Sci., 14: 91-99.

Kuno H. 1968. Differentiation of Basalt Magma. 2a. ed. New York, John Wiley, pp. 623-688.

Leat P.T., Jackson S.E., Thorpe R.S., Stillman C.J. 1986. Geochemistry of bimodal basalt-subalkaline/peralcaline rhyolite provinces within the Southern British Caledonides. Geol. Soc. London, 143: 259 273.

Lima E. F. \& Nardi L. V. S. 1985. Geologia, petrografia e petroquímica das rochas vulcânicas e tufáceas da Região de Volta Grande, Lavras 
do Sul, RS. Acta Geol. Leopoldensia, 20:15-62.

Lima E. F., Wildener W., Lopes R.C., Sander A., Sommer C.A. 1995. Vulcanismo Neoproterozóico associado as bacias do Camaquã e Santa Bárbara - RS. Uma revisão. In: CBG/Núcleo RS, VI Simp. Sul-Brasileiro de Geologia/I Encontro de Geologia do Cone Sul. Boletim de Resumos Expandidos, p.197-199.

Matos D. F., Lima E. F., Sommer C. A., Nardi L. V. S., Liz J. D., Figueiredo A.M. G., Pierosan R., Waichel B. L., 2002. Riolitos Neoproterozóicos Pós-Colisionais na Área do Santuário, Sul do Brasil: Litoquímica, Química Mineral e Origem das Heterogeneidades Texturais, Rev. Bras. Geoc., 32 (2): 255-266.

Meschede M., 1986. A method of discriminating between different types of mid-ocean ridge basalts and continental tholeiítes with the $\mathrm{Nb}-\mathrm{Zr}$-Y diagram. Chem. Geol., 56 (3/4): 207-218.

Paim P. S. G., Chemale F.Jr., Lopes R. C. 2000. A Bacia do Camaquã. In: De Ros, L. F., M. Holz(Eds.) Geologia do Rio Grande do Sul. Porto Alegre, CIGO/UFRGS, 231-374.

Parker D. F. 1983. Origin of the trachyte-quartz, trachyte-peralkalic rhyolite suite of the Oligocene Paisano volcano, Trans-pecos Texas. Bul. Geol. Soc. Amer, 94: 614-629.

Pearce J. A.; Harris N.B. W.; Tindle A. G. 1984. Trace element discrimination diagrams for the tectonic interpretation of granitic rocks. J. Petrol., 25:956-983.

Philipp R.P.; Almeida D.P.M.; Gomes M.E.B.; Pintaúde D.A. 1991. Geoquímica do Granito Bela Vista, Piratini, RS: uma contribuição ao conhecimento do magmatismo alcalino no setor Oriental do Escudo. Acta Geol. Leopoldensia, 14 (34): 95-122.

Philipp R.P., Mesquita M.J., Gomes M.E.B., Almeida D.P.M. 1993. Reconhecimento estrutural e geoquímico dos Granitóides Brasilianos da região de Pelotas, RS. Pesquisas, 20(1):3-13.

Philipp R. P. 1998. A Evolução Geológica e Tectônica do Batólito Pelotas no Rio Grande do Sul. Tese de Doutoramento. Instituto de Geociências, Universidade de São Paulo, 255p.

Philipp R. P. \& Machado R. 2001. Suítes graníticas do Batólito Pelotas no Rio Grande do Sul: petrografia, tectônica e aspectos petrogenéticos. Rev. Bras. Geoc., 31 (3): 257-266.

Philipp R. P., Machado R., Nardi, L. V. S., Lafon J. M. 2002. O magmatismo granítico neoproterozóico do Batólito Pelotas no sul do Brazil: Novos dados e revisão da geocronologia regional. Rev. Bras. Geoc., 32(2): 277-290.
Philipp R.P., Machado R., Chemale,F. Jr. 2003. Reavaliação e Novos Dados Geocronológicos ( $\mathrm{Ar} / \mathrm{Ar}, \mathrm{Rb} / \mathrm{Sr}$ e $\mathrm{Sm} / \mathrm{Nd}$ ) do Batólito Pelotas no Rio Grande do sul: Implicações Petrogenéticas e Idade de Reativação das Zonas de Cisalhamento. Rev. Inst. Geoc., USP, Sér. Cient., São Paulo, 3: $71-84$

Picada R. S. 1971. Ensaio sobre a Tectônica do Escudo Sul-riograndense. Caracterização dos sistemas de Falhas. In: CBG, Congr. Bras. Geol., 25, São Paulo, Anais, 1:167-191.

Ribeiro M. 1977. Mapa Geológico da Quadrícula de Piratini, RS. Fund. Zoob. Est. R. G. Sul, Publ. Esp. 2, Esc. 1:50 000. Porto Alegre, RS.

Silva L. C., Hartmann L. A., McNaughton N. J., Fletcher I. R. 1999. U$\mathrm{Pb}$ zircon dating of Neoproterozoic granite magmatism and collision in the Pelotas Batholith, southernmost Brazil. Intern. Geol. Review, 41:531-551.

Soliani Jr., 1986. Os dados Geocronológicos do Escudo Sul-riograndense e Suas Implicaçôes de Ordem Geotectônica, Instituto de Geociências, Universidade de São Paulo, Tese de Doutoramento, $425 \mathrm{p}$.

Tessari R. \& Giffoni L. E. 1970. Geologia da região de Piratini, Pinheiro Machado e Bagé, Rio Grande do Sul. Bol. Div. Geol., DNPM, $\mathrm{N}^{\circ} .246$, Rio de Janeiro.

Winchester J. A. \& Floyd P. A. 1977. Geochemical discrimination of different magma series and their differentiation products using immobile elements. Chem. Geol. 20:325-343.

Wildner W., Sander A., Lopes R.C. 2004. Estudo petrológico e litogeoquímico de uma parcela do vulcanismo ácido Cambriano do Rio Grande do Sul - Formação Acampamento Velho. Pesquisas 21 (1): 47-57.

Wildner W. \& Nardi L. V. S. 2002 - Caracteristicas Geoquímicas e de Posicionamento Tectônico do Magmatismo Neoproterozóico Aflorante no Platô do Taquarembó -RS. Rev.Bras. Geoc., 32 (2): 169-184.

Wilson M. 1989. Igneous Petrology. Unwin and Hyman, London, $466 \mathrm{p}$.

Wilson M. 1993. Magmatic differentiation. J. Geol. Soc. London, 150:611-624.

Manuscrito A-1610

Revisão aceita em 23 de julho de 2006 